\title{
SOURCES STUDIES
}

Copyright $(\subset) 2018$ by the Kalmyk Scientific Center of the Russian Academy of Sciences

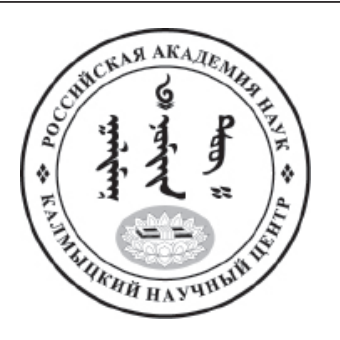

Published in the Russian Federation

Oriental Studies (Previous Name: Bulletin of the Kalmyk Institute for Humanities of the Russian Academy of Sciences)

Has been issued as a journal since 2008

ISSN: 2619-0990; E-ISSN: 2619-1008

Vol. 37, Is. 3, pp. 61-67, 2018

DOI 10.22162/2619-0990-2018-37-3-61-67

Journal homepage: https://kigiran.elpub.ru

UDC 294.321

\section{A History of Tsam in Mongolia by the Abbot of Gandan Monastery Ka-Chu Erdenipel}

Anna D. Tsendina ${ }^{1}$

${ }^{1}$ Ph.D. in Philology (Doct. of Philological Sc.), Professor, Institute for Oriental and Classical Studies, Russian State University for the Humanities; Leading Research Associate, Department of Korea and Mongolia, Institute of Oriental Studies of the RAS; Professor, Higher School of Economics (Moscow, Russian Federation). E-mail: annatsendina@gmail.com

Abstract. The article examines the published excerpt from A History of Tsam in Mongolia, a historical work by the Abbot of Gandan Monastery (Ulaanbaatar) ka-chu Erdenipel (1877-1960) who was one of the last representatives of the classical Mongolian academic tradition with expertise in Buddhist literature and held the position of Gandan's Abbot after the 1944 reinstatement of religious services. As compared to many other educated Buddhists of Mongolia, he is distinguished for written literacy in both Tibetan and Mongolian. Still, only few his works survived to the present day. E.g., he is known to have written Khor-Choijun (A History of Religion in Mongolia) but the work was never discovered, and only a Russian translation of part one is available nowadays. According to Ts. Damdinsuren's diaries, historical works of the priest were kept by his student Dangaasuren who attempted to publish them. Acad. Ts. Damdinsuren's House Museum (Ulaanbaatar) stores two Mongolian-language works by Erdenipel - A History of Khambo Nomyn Khans of Ikh Khüree and A History of Tsam in Mongolia. The composition about Tsam is a manuscript written in ink and feather. Ts. Damdinsuren's inscription says the text was composed in 1942. And the autograph may very possibly have been made by Erdenipel himself. It contains a number of marks and corrections that could have been made by the author only.

A History of Tsam in Mongolia comprises a brief introduction and a list of Mongolian monasteries indicating whether and which specific kind of Tsam (dance) used to be arranged there. The introduction relates about origins of Tsam supposed to have developed from magic rites of Indian Yogâcâryas who made use of special garments and ritual objects during corresponding performances. Erdenipel concludes Tsam appeared in Tibet during the second ('later') dissemination of Buddhism, i.e. after the $11^{\text {th }}$ century AD. Moreover, Tsam was initially performed by monks of the Red Hat sects, while the Yellow Hat Gelugpa introduced Tsam into its rites only under the $1^{\text {st }}$ Panchen Lama Chökyi Gyaltsen in Tashilhunpo and Namgyal Monasteries in the late $16^{\text {th }}-17^{\text {th }}$ centuries.

After that Erdenipel starts explaining the meanings of Tsam moves supposed to suppress antireligious and anti-human demonic powers, and describes attributes of the mystery characters. Special attention is paid to Tsam characters, such as tarnichi who direct Tsam dancers (the so-called Black Hats), or tarnichi who suppress evil powers (masks of oxen and deer) and act as assistants to the Ruler of Hell Chöejel, the dead in the form of skeletons, the merciful Hushan, White Old Man, acharyas and others. 
The most interesting part is a narrative about the dissemination of Tsam in Mongolia. According to Erdenipel, the beginnings of Tsam in Khalkha Mongolia were laid by the $2^{\text {nd }}$ Khalkha Dzaya Pandita Lobsang Nyandag Geleg Namgyal in 1744, though there is no data about that Tsam. Still, concrete facts testify about a 1787 Tsam performance in Erdene Zuu Monastery where it was initiated by the famous Abbot Nomchi Tsorji Dagvadarj (1734-1803). The dance scheme followed the pattern of Namgyal Monastery (Lhasa) but was supplemented with Tsam characters of Sakya Monastery which significantly influenced the rituals in Erdene Zuu.

The capital of Northern Mongolia - Ikh Khüree - first witnessed a Tsam mystery only in 1810. Its principles and scheme also followed the pattern of Tashilhunpo and Namgyal Monasteries. As time passed, the number of Tsam characters increased upon initiatives of different Mongolian public and religious officials. So, there were added masks of lions, Gombo, Chadrabal, Jnanamitra, Dagiradza, Daragsada, Lhamo, etc. Tsam was performed in winters and summers, a complete variant being the privilege of summer ceremonies only.

Keywords: Mongolia, Tsam, ka-chu, Erdenipel

История религиозной мистерии цам в Монголии, в отличие от тибетского цама, тема, разработанная научной мыслью недостаточно полно, несмотря на явный интерес к ней [Позднеев 1880; 1887; Барадийн 1909; Шастина 1935; 1974; Formann, Rintschen 1967; Stein 1972; Heissig 1989; Кимура 1997; Erdeni 1997; Bareja-Starzynska 2012; Teleki 2013; Kollmar-Paulenz, Mununchimeg 2015; и др.]. Это связано, прежде всего, с ограниченностью материала. Исполнение цама в монгольских монастырях было полностью прекращено в 1930-х гг., а костюмы, маски и другие атрибуты практически не сохранились или сохранились в ничтожном объеме. Это же можно сказать и о письменных источниках, ограничивающихся несколькими сочинениями на тибетском языке о цаме в монастырях Эрдэни-дзу и Их-Хурэ, а также некоторыми биографиями церковных иерархов Монголии [История Эрдэни-дзу 1999; Хурэлбаатар 2017]. Тем больший интерес представляет сочинение габджу Эрдэнипэла «История цама в Монголии», до сих пор не известное науке.

Габджу Эрдэнипэл (1877-1960), настоятель монастыря Гандан в г. Улан-Баторе после восстановления в нем религиозной службы в 1944 г., был одним из последних представителей монгольской традиционной учености и знатоков буддийской литературы. Он стоит в ряду таких замечательных деятелей монгольской церкви конца XIX - начала XX в., как Дзава-Дамдин, Гомбоджав и другие, интересы которых были сосредоточены преимущественно вокруг проблем истории Монголии, путей распространения там буддизма, развития культуры. В 2018 г. в Улан-Баторе прошла научная конференция, посвященная деятельности Эрдэнипэла. Судя по ее данным, Эрдэнипэл участвовал в подготовке материалов для составления истории Монголии, буддийской энциклопедии и других современных научных изданий.

Из его письменного наследия до нас дошло не так много [Цендина 2015: 328-330]. Например, известно, что он написал «Хорчойджун», или «Историю религии в Монголии», однако этот труд так и не был обнаружен, сохранился лишь русский перевод первого тома [Железняков, Цендина 2005: 155-247]. В дневниках акад. Ц. Дамдинсурэна есть упоминания о габджу Эрдэнипэле. Судя по ним, какие-то исторические труды ламы (63 листа машинописного текста на современном монгольском языке) имелись у его ученика (?) Дангаасурэна, который пытался их издать [Дневники 1975: 10.22; 1975: 11.16].

В фонде квартиры-музея акад. Ц. Дамдинсурэна в Улан-Баторе хранятся две рукописи Эрдэнипэла, одна из которых - «История цама в Монголии». Это сочинение не только представляет интерес для изучения истории монгольской культуры в целом, но и отражает начальный этап эволюции историографии монголов от традиции к современной истории.

Сочинение о цаме - рукопись, написанная чернилами и пером. Судя по надписи, сделанной Ц. Дамдинсурэном, сочинение было создано в 1942 г. Весьма вероятно, что это автограф самого Эрдэнипэла. Там много помарок и исправлений, которые могли быть сделаны, как представляется, лишь автором. 
Далее следует публикация первой части сочинения Эрдэнипэла «История цама в Монголии» в русском переводе. В другие главы сочинения включены списки монгольских монастырей с сообщениями о том, исполнялся ли там цам или нет, и, если исполнялся, то какой его вид.

$(1)^{1} \mathrm{O}$ том, как возник цам

В буддийском учении Индии о заклинаниях тарни говорится, что после того как [некто] овладеет практикой медитации, т. е. вызыванием и разрушением бурхана-идама, и достигнет в ней мастерства, он получит силу направлять ветер по артериям и двигать [в соответствии с этим] ногами и руками. Кроме этого, сказано, что тарничийогачарий, совершая четыре [магические] действия, должен надевать соответствующие одежды и держать [в руках] нужные предметы. В конце VII в. в Тибете появилась буддийская религия² ${ }^{2}$ В 823 г. или около этого времени приехавший из Индии по приглашению тибетского царя Тисрондэвцана ${ }^{3}$ тарничи и йогачарий Бадамджунай ${ }^{4}$ во время произнесения молитв тантрического обряда, использовал соответствующие одеяния и ритуальные предметы. [Однако] достоверных сведения о цаме и его принадлежностях в ранний период распространения религии в Тибете нет.

В 901 г. тибетский царь Ландарма ${ }^{5}$ полностью уничтожил буддийскую религию в Тибете. Тогда некий лама по имени Лхалун-Балдорджи сшил специальную одежду с особенно широкими рукавами, надел ее, в рукава спрятал лук и стрелы и стал танцевать перед царем, вызывая его любопытство. Обманув царя, он пустил в него стрелу и убил. Так через 70 с лишним лет буддийская религия возродилась. Этот период называют ее поздним периодом. В то время в [сектах] красной религии саджа и гарджудба цам был, но исторических данных о том,

${ }^{1}$ В скобках здесь и далее указывается номер страницы в источнике.

2 Традиционная тибетская историография относит принятие тибетцами буддизма к периоду правления царя Сронцангампо (приблизительно 604-650 гг.).

${ }^{3}$ Царь Тисрондэвцан жил в VIII в. (приблизительно 742-797 гг.).

${ }^{4}$ Индийский проповедник Падмасамбхава (VIII в.).

${ }^{5}$ Тибетский царь, правивший в IX в. (приблизительно 838-842 гг.). каков он был и сколько было его [разновидностей], я не знаю.

В желтой религии в ранний период цам не исполнялся. Позднее в начале XVI в. лама Хайдуб-Санджа-Еше (2) поручил своему ученику, Первому панчен-богдо Чойджи-Джалцану ${ }^{6}$ организовать исполнение цама. Тогда панчен Чойджи-Джалцан создал одежду для цама по образцу одежды, сшитой Лхалун-Балдорджи. Порядок исполнения цама он заимствовал в основном из [канона] саджа и [впервые] поставил его в своем монастыре Дашилхунбо 7 . Ученик Чойджи-Джалцана Пятый далай-лама Агван-Лубсан-Джамцо ${ }^{8}$, взяв этот цам за образец и немного изменив его, инициировал исполнение цама каждый год в дацане Намджал ${ }^{9}$, который находился при его резиденции. Говорят, что в других больших тибетских монастырях желтой религии, кроме этих двух, цама не было.

\section{(3) Смысл танцев}

Движения [персонажей] цама направлены в основном на четыре действия - успокоение [грозных сил], распространение, подчинение и твердое их [подавление].

Танец «гугор» призван поражать всевозможных мощных и зловредных врагов религии.

Движение «авадюмчунг» сильно сотрясает и разрушает жилища и страны всех врагов.

Совершая «луван», убивают зловредных врагов выстрелом [из лука] или уколом [пики].

Совершая «лунгнаг» и «цубма», перемешивают местопребывание врагов и сметают их, как черный смерч.

Совершая «юмчунг», раскачивают жилища препятствующих [вере] врагов и выгоняют их оттуда.

Совершая «шиндой», пригвождают пикой «пурбу» некоторых из зловредных врагов и обездвиживают их.

Совершая «чогши» и «дудтул», усмиряют шимнусов четырех сторон света.

Совершая «дирсуй», ударяют пикой и трезубцем.

${ }^{6}$ Даты жизни - 1570-1662 гг.

7 Ташилхунпо, Дашилхунбо: (тиб.) - монастырь школы гелугпа в Зап. Тибете, резиденция панчен-лам. Основан в 1447 г.

${ }^{8}$ Даты жизни - 1617-1682 гг.

9 Дацан входил в дворцовый комплекс Поталы. Обязанность его лам - религиозные церемонии и службы ради благополучия далай-лам. 
«Ачамджод» - танец, повторяющий шаги умиротворенных чойджинов.

«Дунгган-чаг» и «дунцумчин» изображают танцы разных чойджинов.

(4) «Дунджидма» — танец, изображающий приготовление пути для шествующих главных и высших чойджинов.

«Дзэсум» - танец, подражающий поведению гневных существ.

Танцы этих существ бывают быстрыми и медленными. Однако главные и почитаемые персонажи цама в основном совершают медленные движения, а те, кто ниже их [по рангу], и те, кто сопровождает их, двигаются быстро. В целом они танцуют соответственно четырем основным задачам цама - успокоению, распространению, подчинению и подавлению.

Также задача исполнителей цама двигаться так, чтобы полы и рукава одежды разлетались, будто летит гаруди; встряхивать [головой], будто у льва развеваются волосы на гриве; [двигаться], как тигр, который лениво идет, а потом собирается и сжимается [перед прыжком]; ходить грациозно, словно лев, потягиваясь телом и [вытягивая] гриву; покачиваться в коленях, вертеть руками и ногами, твердо стоять на коленях, изображать всхлипывание и боль, недовольство и плач; при ходьбе двигаться медленно, при взмахах руками и ногами в правую сторону смотреть влево, при взмахах в левую сторону смотреть вправо, при ходьбе вперед смотреть прямо перед собой. Все перечисленные движения танцоры цама и в желтой, и в красной религии совершают одинаково, придерживаясь их как главных принципов.

(5) Исполнитель цама, надев одежды и маску какого-нибудь персонажа, должен думать, что он реально и есть этот персонаж, он должен читать его сердечные заклинания тарни, совершать движения, соответствующие смыслу его танца. Цамбон - это тарничи-йогачарий, руководящий танцорами цама, другие 22 персонажа-шанаг ${ }^{1}$ тоже являются тарничи-йогачариями, все танцуют и совершают движения в одеянии тарничей, исполняющих тантрический обряд. Два персонажа, имеющие головы быка и оленя, под названием «ша» и «ма», являются двумя помощниками Чойджила ${ }^{2}$; они могут с помощью тайной силы менять свои дви-

${ }^{1}$ «Черные шапки» (zhwa nag).

2 Тибетское имя владыки ада Ямараджи (chos rgyal). жения и подавлять [дурные силы] самым жестоким образом. Два скелета танцуют, превращая площадь для цама в кладбище. Хушан-хан - это великий милостынедатель со свитой. Белый старец - властитель счастливой страны, овладевший волшебством благодеяний и [вечной] жизни. Четыре адзара ${ }^{3}$ - индийские созерцатели, обретшие знания четырех истин.

Музыка, исполняющаяся во время танцев цама, заключается в ударах в литавры и барабаны, игре на трубах и дудках, соответственно тому, какие маски цама шествуют [в данный момент], оказывают ли им радостное почтение, угощают ли, просят ли взять на себя заботу о совершении дел, подавляют ли противоборствующих врагов, восхваляют ли, призывают ли счастье и святость, когда они шествуют обратно. Такой порядок установлен издавна.

\section{(6) О появлении цама}

в Халха-Монголии

Известно, что в 1744 г. Второй дзая-пандита Лубсан-Няндаг-Гэлэг-Намджил ${ }^{4}$ для устройства в своем монастыре цама самолично пригласил из Тибета, из монастыря Дашихунбо и Намджал-дацана, учителей цама, однако сведений о том, как это было претворено в жизнь и сколько раз там был исполнен цам, я не нашел. Номчи-цорджи Дагвадарджа из монастыря Эрдэни-дзу установил отношения учителя и ученика с тибетским ламой, умдзадом, аграмбой Рабданом, жившим в Их-Хурэ, и решил в своем монастыре устроить цам. В 1786 г. он обратился к Четвертому Джебдзундамба-хутухте и получил на это разрешение. Тогда он пригласил этого умдзада, аграмбу Рабдана в монастырь Эрдэни-дзу, сделал его учителем цама и под его руководством в 1787 г. устроил первое исполнение цама.

Персонажи того цама были: 1 цамбон; 22 шанага; Гомбо с четырьмя друзьями Чадрабалом, Джинамитрой, Дагирадзой и Дарайшадом - всего 5; Гонгор с друзьями - пятеро, а с Хандо - 6; Гомбогур с друзьями - Гаджати, Бадара, Будара, Лхамо, Ралджигма, Нодджин с супругом, а также львиноголовый, тигроголовый, два медведя - черный и рыжий пещерные медведи - всего 12; кроме того, сопровождающие Гомбогура из внешних или нижних [рядов] - 4 черные женщины, или мамо;

\footnotetext{
${ }^{3}$ Искаженное «ачарья».

${ }^{4}$ Халхаский дзая-пандита.
} 
4 тарничи-заклинателя-шанага; 4 гэлунга; 4 богатыря-простолюдина; Чойджил; Дзамунди; Лхамо; два Дунджангни с головами льва и крокодила; Шалши с супругом двое; Джамсаран; Ригби-Лхамо; Лайгон; Дуртуддагбо с супругой - двое; «ша» и «ма» - двое; Лайхан «ша» - один; всего около 70 персонажей участвовали в первом цаме, который следовал в основном канону тибетского Намджил-дацана. Из канона саджа (7) были позаимствованы Гомбогур и его свита - всего 28 персонажей. Есть сведения, что впоследствии персонажи были дополнены масками из монастырей Дзаяпандиты, Чин-Суджигту-номун-хана, Манджушри-ламы, однако какие это были персонажи, из какого монастыря и какие маски были позаимствованы, точных данных я не обнаружил.

В Их-Хурэ также появилось желание организовать исполнение цама. Инициаторы обратились с просьбой к Эрдэни-шандзодбе, Цэцэн-тойну Гомбоджабу и монгольским сановникам. Получили разрешение Четвертого Джебдзундамба-хутухты, в 1819 г. устроили цам, соединив каноны Дашилхунбо и Намджил-дацана. В этом цаме участвовали следующие персонажи: 1 цамбон и 22 шанага - это 23 персонажа, которые являются тарничами, совершающими подавление [демонов]; Эрлик-хан Чойджил с Дзамунди, его сопровождающие эрлики: белый Явади, желтый Чусанг, красный Мигба, синий Ралбадзаргу, красный Мигмар, белый Дилва, темно-синий Лангучин, черный Дудубдагбо, «ша» и «ма» с головами оленя и сарлака; эти 12 персонажей отвечают в основном за устранение препятствий и вражеских сил религии. Гонгор и Намасарай - белого цвета, у них просят магической силы, связанной с вещественным [миром], в особенности такой, которая [приумножает] имущество. Вачирбани - синий, у него просят очищения 8 областей черной стороны. У трех персонажей - с головой льва, которого называют Сэндонма, с головой тигра и медведя - просят дать отпор проклятиям, которые насылают внешние [силы]. Джамсаран, Ригбилхамо, Лайгон и 8 их маленьких друзей - эти 11 являются гениями-хранителями, которых почитают все в Их-Хурэ, (8) поэтому им поручают отвращать всевозможные дурные силы, вредящие Их-Хурэ. К ним прибавили четыре персонажа сабдаков четырех гор: с головами синего старика, свиньи, гаруди и т. д. Четыре адзара, сопровождающие этих гениев-хранителей, изображают поведение тарничей, их называют индийскими тарничами. Два скелета превращают площадку для цама в кладбище трупов врагов религии и устанавливают там свое владычество. Два багатура осуществляют охрану. Люди в 10 различных масках и одеждах гениев-хранителей защищают каждый свою сторону света. Хушан-хана с 8 юношами называют великим ханом-милостынедателем. Одного человека в одежде тарнича называют охранителем ветров и дождей. Добавлен еще один человек с головой черной птицы. Белый старец, говорят, является хозяином местности, владеющим секретом долгой жизни, он дает счастье. Монгольские амбани, ваны и нояны того времени добавили двух львов. Позднее в 1874 г. амбань и цэцэн-хан прибавили маски Гомбо, Чадрабала, Джанамитры, Дагирадзы, Дарагсада, Лхамо и двух Дунгджанов - всего 8.

Этот цам исполнялся каждый год два раза - зимой и летом. Летом - долго, в полном объеме, а зимой - коротко, в сокращенном виде. Однако их суть и задачи были одинаковыми.

Проведением цама руководил цамбон, он учил и давал устные наставления о том, какие движения, полные значения, должны совершать ученики. Непосвященный же человек не видит больше, чем внешнее действие.

\section{ЛИТЕРАТУРА И ИСТОЧНИКИ / REFERENCES AND SOURCES}

Барадийн 1909 - Барадийн Б. Цам Миларайбы: (из жизни в Лавране) // Записки Императорского Русского Географического Общества по отделу этнографии: Сб. в честь 70-летия Г. Н. Потанина. 1909. Т. 39. С. 135147. [Baradiyin B. Milarepa's Tsam (glimpses of life in Labrang). Zapiski Imperatorskogo Russkogo Geograficheskogo Obschestva po otdelu etnografii: Sb. v chest' 70-letiya G. N. Potanina. 1909. Vol. 39. Pp. 135-147].

Дневники 1975 - Дневники академика Цэндийна Дамдинсурэна. 1975. Рукописи хранятся в архиве А. Д. Цендиной. [Dnevniki akademika Tsendiyna Damdinsurena. 1975. Ruk. khranyatsya $v$ arkhive A. D. Tsendinoy [Diaries by prof. Tsendiin Damdinsüren. 1975. Manuscripts from A. Tsendina's archive].]

Жуковская 1977 - Жуковская Н. Л. Ламаизм и ранние формы религий. М.: Наука, Гл. ред. вост. лит., 1977. 200 с. [Zhukovskaya N. L. 
Lamaizm i rannie formy religiy [Lamaism and early forms of religion]. Moscow: Nauka, Vost. Lit., 1977. 200 p.]

История Эрдэни-дзу 1999 - История Эрдэнидзу. Факсимиле рукописи. Пер с монг., введ., коммент. и прилож. А. Д. Цендиной. М.: Вост. лит. РАН, 1999. 255 с. [Istoriya Erdeni$d z u$ [A history of Erdene Zuu]. A facsimile of the manuscript. A. D. Tsendina (foreword, transl., comment. and suppl.). Moscow: Vost. Lit., 1999. 255 p.]

Кимура 1997 - Кимура Аяко. Монголын Хүрээ цамыг бусад орны цамтай харьцуулан судалсан нь: автореф. дис. ... д-ра ист. наук. Улаанбаатар: Монгол улсын их сургууль, 1997. 52 x. [Kimura Ayako. Mongolyn Khüree tsamyg busad orny tsamtay khar'tsuulan sudalsan n' [Ikh Khüree Tsam and other types of the dance: a comparative study]. A PhD thesis abstract. Ulaanbaatar: National University of Mongolia, 1997. 52 p.]

Позднеев 1887 - Позднеев А. М. Очерки быта буддийских монастырей и буддийского духовенства в Монголии в связи с отношением сего последнего к народу. СПб.: Тип. Имп. акад. наук. 1887. 492 с. [Pozdneev A. M. Ocherki byta buddiyskikh monastyrey $i$ buddiyskogo dukhovenstva $v$ Mongolii $v$ svyazi $s$ otnosheniem sego poslednego $k$ narodu [Essays on the life of Buddhist monasteries and clergy in Mongolia in connection with the latter's relation to the people]. St. Petersburg: Imperial Acad. of Sc., 1887. 492 p.]

Позднеев 1880 - Позднеев А. М. Ургинские хутухты: исторический очерк их прошлого и современного быта. СПб: Тип. брат. Пантелеевых. 1880. 84 с. [Pozdneev A. M. Urginskie khutukhty: istoricheskiy ocherk ikh proshlogo $i$ sovremennogo byta [Urga khutuktus: a historical overview of their past and present life]. St. Petersburg: Panteleevy Brothers, 1880. 84 p.]

Хүрэлбаатар 2017 - Хүрэлбаатар Л. Монгол цамын цоохор тэмдэглэл // Утга зохиол судлагч, товдч эрдэмтэн Лхамсурэнгийн Хурэлбаатар. Улаанбаатар: «Жиком пресс» XXK, 2017. C. 83-142. [Khurelbaatar L. Various notes on the Mongolian Tsam. Utga zokhiol sudlagch, tovdch erdemten Lkhamsurengiyn Khurelbaatar [Literary researcher and Tibetologist Lhamsurengiin Hurelbaatar]. Ulaanbaatar: «Zhikom Press» Ltd., 2017. Pp. 83-142] (In Mong.).

Цендина 2015 - Цендина А. Д. О настоятеле монастыряГандангабджуЭрдэнипэле (18771960) и его сочинениях на монгольском языке
// Россия и Монголия в первой половине XX века: концептуальные вопросы российскомонгольских отношений (диломатия, экономика, наука). Сб. науч. тр. Кн. 5. Улан-Батор; Иркутск: Изд-во Байкальского ун-та, 2015. С. 328-330. [Tsendina A. D. About the abbot of Gandan Monastery ka-chu Erdenipel (1877-1960) and his Mongolianlanguage compositions. Rossiya i Mongoliya $v$ pervoy polovine $X X$ veka: kontseptual'nye voprosy rossiysko-mongol'skikh otnosheniy (dilomatiya, ekonomika, nauka). Sb. nauch. tr. Vol. 5. Ulaanbaatar-Irkutsk: Baikal State University, 2015. Pp. 328-330].

Цендина, Железняков 2005 - Цендина А. Д., Железняков А.C. История в трудах ученых лам. М.: Товарищество научных изданий КМК, 2005. 275 с. [Tsendina A. D., Zheleznyakov A. S. Istoriya $v$ trudakh uchenykh lam [History in the works of educated clergymen]. Moscow: KMK Academic Publications Association, 2005. 275 p.]

Шастина 1935 - Шастина Н. П. Религиозная мистерия цам в монастыре Дзун Хурэ // Современная Монголия. № 1. Улан-Батор, 1935. C. 92-113. [Shastina N. P. Tsam religious mystery in Dzun Khuree Monastery. Sovremennaya Mongoliya. No. 1. Ulaanbaatar, 1935. Pp. 92-113].

Шастина 1974 - Шастина Н. П. Следы примитивных религий в ламаистской мистерии цам // Исследования по восточной филологии. М.: Наука, 1974. С. 306-318. [Shastina N. P. Traces of primitive religions in the Lamaist Tsam mystery (dance). Issledovaniya po vostochnoy filologii. Moscow, 1974. Pp. 306-318].

Bareja-Starzynska 2012 - Bareja-Starzynska A. Description of the Erdeni Zuu Monastery (Including čam Ritual) Based on Notes from the Kotwicz Expedition. In the Heart of Mongolia. $100^{\text {th }}$ Anniversary of W. Kotwicz's Expedition to Mongolia in 1912. Jerzy Tulisow et al. (eds.). Cracow: Polish Academy of Arts and Sciences, 2012. Pp. 131-189.

Erdeni 1997 - Erdeni. Mongrol čam. Beijing: National Publ. House, 1997. 159 p.

Formann, Rintschen 1967 - Formann $W$., Rintschen B. Lamaistische Tanzmasken (Der Erlik-Tsam in der Mongolia) [Lamaist dance masks (Erlik Tsam in Mongolia)]. Leipzig: Koehler und Amelang, 1967. 144 p.

Heissig 1989 - Heissig $W$. Der Tsam-Tanz und seine Masken [Tsam dance and ist masks]. Die Mongolen. Begleitband zur Ausstellung im Haus der Kunst München 22. März bis 28. 
Mai 1989. W. Heissig, G.C. Müller (eds.). Innsbruck: Pinguin-Verlag, 1989. Pp. 240-244.

Kollmar-Paulenz, Mununchimeg 2015 - KollmarPaulenz K., Mununchimeg B. Der mongolische Maskentanz (Tsam) in Vergangenheit und Gegenwart [The Mongolian mask dance (Tsam) in past and present]. Asia. 2015. No. 69(3). Pp. 625-683.
Stein 1972 - Stein R. F. Tibetan Civilization. Stanford University press, 1972. 336 p.

Teleki 2013 - Teleki $K$. The Khüree-Tsam and its Relation with the Tsam Figures of the Leder Collection. The Mongolian Collection Retracing Hans Leder. Maria-Lhatarina Lang, Stefan Bauer (eds.). Wien: Austrian Academy of Sciences, 2013. Pp. 76-83.

УДК 294.321

\section{«История цама в Монголии» - сочинение настоятеля монастыря Гандан габджу Эрдэнипэла}

Анна Дамдиновна Цендина ${ }^{1}$

${ }^{1}$ доктор филологических наук, профессор, Институт восточных культур и античности Российского государственного гуманитарного университета, ведущий научный сотрудник, Институт востоковедения РАН, профессор НИУ «Высшая школа экономики» (Москва, Российская Федерация). E-mail: annatsendina@gmail.com

Аннотация. Статья посвящена публикации фрагмента исторического труда настоятеля монастыря Гандан в г. Улан-Баторе габджу Эрдэнипэла «История цама в Монголии». Эрдэнипэл (1877-1960) - один из последних представителей монгольской традиционной учености и знатоков буддийской литературы, настоятель монастыря Гандан в г. Улан-Баторе, избранный после восстановления в нем религиозной службы в 1944 г. Из его письменного наследия до нас дошло не много. Известно, что он написал «Хор-чойджун», или «Историю религии в Монголии», однако этот труд не обнаружен, сохранился лишь русский перевод первого тома. В музее-квартире акад. Ц. Дамдинсурэна в г. Улан-Баторе хранятся два сочинения габджу Эрдэнипэла на монгольском языке - «История хамбо-номун-ханов ИхХурэ» и «История цама в Монголии». Сочинение о цаме - рукопись, написанная чернилами и пером. Судя по надписи, сделанной Ц. Дамдинсурэном, сочинение было создано в 1942 г. Весьма вероятно, что это автограф самого Эрдэнипэла. Рукопись содержит много помарок и исправлений, которые могли быть сделаны, как представляется, лишь автором.

«История цама в Монголии» состоит из небольшого введения и списка монгольских монастырей с указанием, устраивалась ли там мистерия цам, и, если устраивалась, то какой из ее видов. Во введении автор рассказывает об истоках цама, которые он видит в магических обрядах индийских йогачариев, использовавших во время их исполнения специальные одеяния и ритуальные предметы. Появление цама в Тибете Эрдэнипэл относит ко времени т. н. «позднего периода» распространения буддизма в Тибете после XI в. При этом цам исполняли монахи только красношапочных сект, а желтошапочная секта гэлуг ввела в свои ритуалы цам только при первом Панчен-ламе Чойджи-Джалцане в XVI-XVII вв. Первоначально цам исполнялся лишь в монастырях Дашилхунпо и Намджал.

Наиболее интересным представляется рассказ о распространении цама в Монголии. По сведениям Эрдэнипэла, начало цаму в Халха-Монголии положил Второй халхаский Дзаяпандита Лубсан-Няндаг-Гэлэг-Намджил в 1744 г. В 1787 г. в монастыре Эрдэни-дзу была впервые представлена мистерия цам по инициативе знаменитого настоятеля этого монастыря Номчи-цорджи Дагвадарджа (1734-1803). В столице Северной Монголии Их-Хурэ цам впервые был исполнен в 1810 г.

Ключевые слова: Монголия, цам, габджу, Эрдэнипэл 